\title{
Manipulations During the Second, but not the First, Week of Life Increase Susceptibility to Cocaine Self-Administration in Female Rats
}

\author{
Shelly B Flagel', Delia M Vázquez ${ }^{2,3,1}$ and Terry E Robinson*,4,1 \\ 'Neuroscience Program, University of Michigan, Ann Arbor, MI, USA; '2Department of Pediatrics, University of Michigan, Ann Arbor, MI, USA; \\ ${ }^{3}$ Mental Health Research Institute, University of Michigan, Ann Arbor, MI, USA; ${ }^{4}$ Psychology Department, University of Michigan, Ann Arbor, MI, \\ USA
}

\begin{abstract}
We compared the effects of manipulations during week I vs week 2 of life on the propensity to self-administer cocaine. Pups received daily subcutaneous saline injections, were handled briefly, or remained undisturbed during their respective treatment periods. Animals handled during the second week of life exhibited increased locomotor response to novelty when tested on postnatal day (PND) 48, compared to all other groups. Rats were implanted with jugular catheters on PND 70 and then given the opportunity to self-administer $(0.125 \mathrm{mg} / \mathrm{kg} /$ infusion) cocaine for 5 consecutive days ( $\mathrm{h}$ sessions). The dose was then raised to $0.25 \mathrm{mg} / \mathrm{kg} /$ infusion for $5 \mathrm{days}$ and to $0.5 \mathrm{mg} / \mathrm{kg} /$ infusion for the final 5 days of testing. Only animals manipulated during the second week of life acquired drug-taking behavior. These effects were both stimulus- and gender-specific. Females handled during the second week of life acquired cocaine selfadministration (SA) at the lowest dose, and females injected during the second week of life acquired at the intermediate dose. Males injected during the second week of life showed a similar, but more variable, drug-taking pattern. There were no group differences in serum corticosterone response to novelty, although relative to undisturbed animals and those manipulated in the first week of life, female animals manipulated during the second week of life had lower basal expression of hippocampal glucocorticoid receptor mRNA in adulthood. We conclude that the second week of life in the rodent is a sensitive period during which manipulations result in a more vulnerable phenotype for the acquisition of cocaine SA.

Neuropsychopharmacology (2003) 28, I74I-I75I, advance online publication, 23 July 2003; doi: | 0.1038/sj.npp. 1300228
\end{abstract}

Keywords: postnatal manipulation; glucocorticoid receptor; self-administration; sex difference; stress; vulnerability

\section{INTRODUCTION}

Many people experiment with potentially addictive drugs, but relatively few become addicts (O'Brien et al, 1986; Wagner and Anthony, 2002), indicating that there is considerable individual variation in susceptibility to addiction. Susceptibility to drug use and addiction is influenced by both environmental and genetic factors that appear to be associated with particular behavioral and neurochemical phenotypes (Enoch and Goldman, 1999; Gordon, 2002; Nestler, 2000; Piazza and Le Moal, 1996). In humans, early life stressors such as childhood abuse and neglect have been associated with an early onset of drug use (Moss et al, 1999; Tarter et al, 1999) and an increased risk of becoming an

*Correspondence: Dr TE Robinson, Biopsychology Program, Department of Psychology, The University of Michigan, 525 E. University (East Hall), Ann Arbor, MI 48 109, USA, Tel: + I 734763 436I, Fax: + I 734 763 7480, E-mail: ter@umich.edu

Received 25 October 2002; revised 01 May 2003; accepted 05 May 2003

Online publication: I5 May 2003 at http://www.acnp.org/citations/ Npp05 I 50394/default.pdf addict (Dinwiddie et al, 1992; Duncan, 1977; Guteirres et al, 1994). In addition, studies using nonhuman primates have indicated a relationship between lack of maternal care early in life and excessive alcohol consumption as adults (Higley and Bennett, 1999; Higley et al, 1991). These and other findings suggest that early life events alter the development of specific neurobiological systems and thereby increase susceptibility to drug use and addiction later in life (Kehoe et al, 1998a, b, 1996; Levine, 1975; Meaney et al, 2002; Vazquez et al, 2002).

In recent years, rodent models have been used to investigate the relationship between early life stress and vulnerability to drug use in adulthood. Most of these studies suggest that early manipulations lead to increased drugtaking behavior in adulthood. For example, rat pups separated from their mothers during the first few weeks of life drink more alcohol and self-administer more cocaine than do control animals (Huot et al, 2001; Kosten et al, 2000; Matthews et al, 1999). Rats given chronic daily injections (of isotonic saline) exclusively during the second week of life consume more alcohol as adults compared to handled controls (Vazquez et al, 2002). In contrast to the 
paradigms mentioned above, brief postnatal handling during the first 12 days of life seems to be protective, resulting in an attenuation of amphetamine-induced conditioned place preference in adulthood (Campbell and Spear, 1999), as well as less robust psychomotor sensitization to cocaine (Li et al, 2003). Taken together, these reports suggest that there is a vulnerable period during development in which specific environmental events lead to individual differences in drug-taking behavior.

The exact timing of a stressor, the regimen of exposure, and the resulting maternal behavior elicited by early life manipulations seem to play a critical role in determining long-term outcomes (Denenberg and Bell, 1960; Denenberg and Zarrow, 1971; Levine and Lewis, 1959; Nunez et al, 1996; Ogawa et al, 1994; Russell, 1971). For example, manipulations during the first week of life have different effects on maternal behavior and limbic-hypothalamicpituitary-adrenal (LHPA) axis development from manipulations in the second week of life (Grota and Ader, 1969, 1974; Levine and Lewis, 1959; Meaney and Aitken, 1985; Reisbick et al, 1975). Likewise, we would expect to see differences in drug-taking behavior in animals who were manipulated during week 1 compared to week 2 of life. To examine this hypothesis, we compared the effects of daily subcutaneous (s.c.) saline injections (Dent et al, 2000; Smith et al, 1997; Vazquez et al, 2002) and handling during week 1 $v s$ week 2 of life on the propensity to acquire cocaine selfadministration (SA) in adulthood. In addition, we examined locomotor response to novelty, adrenocortical responsivity, and basal stress-related gene expression in adult animals.

\section{MATERIALS AND METHODS}

\section{Animals}

Male and female adult Sprague-Dawley rats (Charles Rivers, Wilmington, MA) were housed in accordance with the National Institutes of Health Guide for the Care and Use of Laboratory Animals (http://oacu. od.nih.gov/regs/guide/ guidex.htm). Upon arrival, animals were housed three per cage (polycarbonate cages $-25 \times 48 \times 20 \mathrm{hcm}$ ) with corncob bedding on the floor. The room was kept at a constant temperature $\left(25 \pm 2^{\circ} \mathrm{C}\right)$, and the lights were on a $12: 12 \mathrm{~h}$ light-dark cycle (lights on at 0700). All animals were provided food and water ad libitum. Following a 7-day acclimation period, three female rats were placed in a cage with one male rat for a period of 10 days to allow them to breed. Females were then housed three to a cage until estimated gestational day 18 , at which point they were housed individually. On the day of birth, postnatal day (PND) 1, each litter was culled to 10-12 pups and placed in a clean cage with the dam. Whenever possible, equal numbers of males and females were represented in each litter. A total of 30 litters were used in these experiments ( $n=6$ litters/group).

\section{Early Life Treatment}

Each litter was assigned to one of five treatment groups: (1) rats who received s.c. saline injections $(0.9 \% \mathrm{NaCl} ; 0.01 \mathrm{ml} / \mathrm{g}$ body weight) during the first week of life (PND 2-8; SAL 1), (2) rats who were handled during the first week of life
(HAN 1), (3) rats who received saline injections during the second week of life (PND 8-14; SAL 2), (4) rats who were handled during the second week of life (HAN 2), and (5) rats who were left undisturbed throughout the first 2 weeks of life (UND). Injection or handling (SAL and HAN groups) occurred between the hours of 1100 and 1300. For these groups, the dams were removed from the homecage and placed in a clean holding cage for a period of $10 \mathrm{~min}$, while the homecage containing the pups was transported to a room adjacent to the colony. Once in the adjacent room, the cage was placed on an electric heating pad set at $30-33^{\circ} \mathrm{C}$ to keep the pups warm. Pups in the HAN group were weighed and measured, which took approximately $10 \mathrm{~min}$, and then returned to the colony room where the dam was placed back into the homecage. Pups in the SAL group were treated exactly as the HAN group, but in addition they received a s.c. injection ( $30 \mathrm{G} 1 / 2$ needle; administered in scruff of neck) of sterile saline immediately after the measurements were obtained. Pups in the UND group remained undisturbed in the colony room until PND 14. On PND 14, the cages of all of the litters were changed/cleaned for the first time since birth. The litters were then left undisturbed until PND 21, at which point the pups were weaned from their mothers and housed in groups of six with littermates of the same sex. Animals remained undisturbed (except for biweekly husbandry) from the time of weaning until PND 35 when they were again separated and housed in same-sex groups of three. The animals were then left undisturbed (except for bi-weekly husbandry) until PND 45 (see below).

\section{PROCEDURES}

\section{Locomotor Response to Novelty}

Locomotor response to a novel environment was assessed in all animals between PND 48 and 52. The animals were briefly handled for 1-2 min daily 3 days prior to testing. Testing for exploratory behavior began at $0900,2 \mathrm{~h}$ after light onset. The novel environment consisted of a $25 \times 48 \times 20 \mathrm{~cm}$ tinted polycarbonate cage (Allentown Caging Equipment, Inc., Allentown, PA) with pine-shave bedding. Locomotor activity was monitored with two banks of photocells $(29 \mathrm{~cm}$ apart in length and $9 \mathrm{~cm}$ apart in width) connected to a microprocessor. The number of crossovers between the photocells was recorded and summed over the 120-min testing period. Male and female rats were tested separately, and cages were thoroughly cleaned between testing sessions to eliminate odors. Vaginal lavages were performed on the female animals immediately following locomotor testing to approximate the phase of their estrous cycle. To control for an effect of handling, male animals were handled in a similar manner (lifting the tail) for the same amount of time as the females. Despite previous reports suggesting that circulating sex hormone levels affect locomotor activity (Colvin and Sawyer, 1969; Sell et al, 2000; Slob et al, 1981; Wang, 1923), we found no differences in our female animals which were due to the phase of their estrous cycle. Thus, all the females were included in the dataset. Due to equipment failure, however, some animals (males and females) were not included in the final analysis. Therefore, the total number of animals analyzed for locomotor response to novelty are as follows:

Neuropsychopharmacology 
females-UND, $n=32$; HAN 1, $n=39$; HAN 2, $n=34$; SAL $1, n=35$; SAL $2, n=35$; males - UND, $n=37$; HAN 1 , $n=32$; HAN 2, $n=33$; SAL $1, n=31$; SAL $2, n=33$.

\section{Corticosterone Response to Novelty}

Approximately 1 week following the assessment of locomotor response to novelty (PND 55-63), plasma was obtained from all animals for analysis of corticosterone (CORT). Blood samples were collected between the hours of 0900 and 1130. Using the tail-nick method (see below), sampling occurred at $15,30,60$, and $120 \mathrm{~min}$ following exposure to a light-dark box ( $5 \mathrm{~min}$ - novelty stress). A basal time point $(0 \mathrm{~min})$ was obtained on the morning before the procedure. Briefly, a small incision was made toward the tip of the rat's tail while the rat was loosely held by hand during blood sampling. Blood was collected from the tail vein into microcentrifuge tubes containing EDTA and then spun at $14000 \mathrm{rpm}$ for $3 \mathrm{~min}$. Serum was collected from the centrifuged sample and stored at $-20^{\circ} \mathrm{C}$ until further analysis. CORT levels were determined via radioimmunoassay (ICN Biomedicals, Costa Mesa, CA). The sensitivity of the CORT assay was $1.25 \mu \mathrm{g} / \mathrm{dl}$.

\section{SELF-ADMINISTRATION}

\section{Subjects and Surgery}

Half of the animals per litter (three males, three females in a litter of 12) were randomly selected and evaluated for SA behavior. The remaining animals were killed on PND 70 in order to obtain measures of LHPA activity in tissue prior to drug exposure (see below). Rats selected to proceed to SA were anesthetized with a ketamine $(100 \mathrm{mg} / \mathrm{kg})$, xylazine $(20 \mathrm{mg} / \mathrm{kg})$, and acepromazine $(20 \mathrm{mg} / \mathrm{kg})$ solution in a $1-$ $\mathrm{ml} / \mathrm{kg}$ volume. A chronic indwelling catheter was placed into the external jugular vein using procedures described previously (Browman et al, 1998; Crombag et al, 1996; Robinson et al, 2001; Weeks, 1972). Briefly, a silicone catheter $\left(0.012^{\prime \prime} \times 0.025^{\prime \prime} \times 0.0065^{\prime \prime}\right.$; A-M Systems, Inc., Carlsborg, WA) was inserted into the external jugular vein and passed s.c. to an infusion port mounted between the shoulder blades, similar in design to that described by Caine et al (1993). During the 3-5 days recovery period following surgery, rats received a daily infusion of the antibiotic gentamycin ( $1 \mathrm{mg} / \mathrm{kg}$, i.v.) and a $0.1 \mathrm{ml}$ sterile heparinsaline solution (30 USP U/ml) to prevent clogging of the catheter. In addition, before the start of each SA session, the catheter was flushed with $0.1 \mathrm{ml}$ of the saline-heparin solution.

On the day prior to SA testing, catheter patency was assessed by injecting $0.1-0.2 \mathrm{ml}$ of thiopental sodium (Pentothal ${ }^{\mathbb{R}}-20 \mathrm{mg} / \mathrm{ml}$ sterile $\mathrm{H}_{2} \mathrm{O}$ ) into the catheter. Rats who did not lose muscle tone within 2-3s were excluded from the experiment. Animals were again checked for catheter patency following the 15-day test period. Only those animals who passed both catheter patency tests were included in the analyses. The total number of animals included in the final analyses for SA behavior are as follows: females-UND, $n=8$; HAN $1, n=10$, HAN 2, $n=8$; SAL 1 , $n=10$; SAL 2, $n=8$; males-UND, $n=10$; HAN $1, n=8$; HAN 2, $n=8$; SAL 1, $n=9$; SAL 2, $n=10$. No more than two rats per sex per litter were included, with six litters represented per group.

\section{Apparatus}

Animals were placed in an operant chamber and the infusion port was attached to a liquid swivel, which was connected to a pump-driven syringe (Razel Scientific Instruments, Stamford, CT). The SA cage $(41 \times 24 \mathrm{~cm}$ floor area, $26 \mathrm{~cm}$ high; MED associates, St Albans, VT) was equipped with two holes located $6 \mathrm{~cm}$ above the grid floor and placed on one of the 24 -cm-wide sides. The house light was illuminated at the onset of the session and remained on until the active hole was poked. Nose poking in the 'active' hole (FR1) resulted in a $30 \mu$ infusion of the cocaine solution over a period of $3 \mathrm{~s}$. In addition, the house light turned off and the active hole was illuminated for the duration of the drug infusion ( $3 \mathrm{~s})$. Subsequent nose pokes during the infusion period were recorded, but had no effect. Nose pokes in the 'inactive' hole were without consequence throughout the session. The number of nose pokes in both holes and the number of infusions were recorded with MED Associates Instrumentation Software for Research (St Albans, VT). To eliminate odors, male and female rats were tested in different chambers and the operant cages were thoroughly cleaned between testing sessions.

\section{SA Testing}

Animals began testing for cocaine SA around PND 75. SA methods were adapted from Marinelli and White (2000) and Kosten et al (2000). Daily 1-h SA sessions were conducted between the hours of 1300 and 1800 for 15 consecutive days. Rats received one cocaine dose for 5 consecutive days, followed by the next doses in ascending order. The cocaine doses increased from 0.125 to 0.25 , to $0.5 \mathrm{mg} / \mathrm{kg}$ per infusion (cocaine $\mathrm{HCl}$, Mallinkrodt Pharmaceuticals, Hobart, NY; dissolved in PBS, $\mathrm{pH} 7.4$ ).

\section{IN SITU HYBRIDIZATION}

\section{Tissue Collection}

On PND 70, half of the animals from each litter (three males, three females) were killed by decapitation between the hours of 0800 and 0900 . Brains were immediately removed, frozen in isopentane $\left(-30\right.$ to $\left.-40^{\circ} \mathrm{C}\right)$, and stored at $-80^{\circ} \mathrm{C}$. Six female brains from each group were used for in situ hybridization. Coronal brain sections $(15 \mu \mathrm{m})$ were cut on a cryostat (at $180 \mu \mathrm{m}$ intervals) and thaw mounted onto Superfrost/Plus slides (Fisher Scientific, Pittsburgh, PA, USA). Regions of interest were identified with Cresyl Violet staining. Slides were stored at $-80^{\circ} \mathrm{C}$ until processing for in situ hybridization.

\section{Riboprobes}

${ }^{35}$ S-UTP-labeled cRNA probes to corticotropin-releasing hormone $(\mathrm{CRH})$, mineralocorticoid receptor $(\mathrm{MR})$, and glucocorticoid receptor (GR) were produced using standard in vitro transcription methodology. The CRH cRNA probe was produced using a 353 base-pair fragment derived from 
a rat cDNA clone that includes exon 2, the peptide region of the rat CRH gene (courtesy of R Thompson, University of Michigan, USA). The MR probe was synthesized from a 347 base-pair PstI-EcoRI fragment of MR cDNA (Patel et al, 1989) ligated into PGEM 3 . The GR probe was synthesized from a 544 base-pair fragment of GR cDNA subcloned into the XbaI-EcoRI site of pGEM 4. The specificity of the GR and MR riboprobes has been previously confirmed (Herman et al, 1989). The riboprobes were synthesized utilizing the SP6, T3, or T7 transcription systems in a standard labeling reaction mixture consisting of: $1-\mu \mathrm{g}$ linearized plasmid, $5 \times$ of the appropriate transcription buffer (Invitrogen, Carlsbad, CA, USA), $125 \mu \mathrm{Ci}^{3}{ }^{35} \mathrm{~S}$-UTP (Amersham Biosciences, Arlington Heights, IL, USA), $150 \mu \mathrm{M}$ of NTPs, $12.5 \mathrm{mM}$ dithiothreitol (DTT), $20 \mathrm{U}$ RNase inhibitor and $6 \mathrm{U}$ of the appropriate polymerase (Invitrogen, Carlsbad, CA, USA). The reaction mixture was incubated for $60-90 \mathrm{~min}$ at $37^{\circ} \mathrm{C}$, treated with DNase I RNA free for $15 \mathrm{~min}$ at room temperature, followed by filtration over a Sephadex G50-50 Quick Spin Column (Roche Diagnostics Corp., Indianapolis, IN, USA) to separate the labeled probe from free nucleotides.

\section{In Situ Hybridization}

Tissue sections were transferred from storage and fixed in $4 \%$ paraformaldehyde at room temperature. After $1 \mathrm{~h}$ of fixation, slides were rinsed in isotonic phosphate-buffered saline and then treated with proteinase $\mathrm{K}(0.1 \mu \mathrm{g} / \mathrm{ml}$ in $100 \mathrm{mM} \mathrm{Tris} / \mathrm{HCl}, \mathrm{pH} 8.0$ ) at $37^{\circ} \mathrm{C}$ for $10 \mathrm{~min}$. Subsequently, sections underwent successive washes in purified water ( $1 \mathrm{~min}$ ), $0.1 \mathrm{M}$ triethanolamine ( $\mathrm{pH} 8.0$, plus $0.25 \%$ acetic anhydride) for $10 \mathrm{~min}$, and $2 \times \mathrm{SSC}(0.3 \mathrm{mM} \mathrm{NaCl}, 0.03$ sodium citrate, $\mathrm{pH} 7.2$ ) for $5 \mathrm{~min}$. Sections were then dehydrated through graded alcohols and air-dried overnight. Postfixed sections were hybridized with $\geqslant 1.0 \times 10^{6}$ counts per minute $(\mathrm{cpm}){ }^{35} \mathrm{~S}$-UTP-labeled riboprobe in a total volume of $25 \mu \mathrm{l}$ hybridization buffer ( $50 \%$ formamide, $10 \%$ dextran sulfate, $3 \times$ SSC, $50 \mathrm{mM}$ sodium phosphate buffer ( $\mathrm{pH}$ 7.4), $1 \times$ Denhardt's solution, $0.1 \mathrm{mg} / \mathrm{ml}$ yeast tRNA, and $10 \mathrm{mM}$ dithiothreitol). Brain sections were coverslipped and incubated overnight at $55^{\circ} \mathrm{C}$. On the following day, sections were rinsed and washed twice in $2 \times$ SSC for $5 \mathrm{~min}$ each and then incubated for $1 \mathrm{~h}$ in RNase A $(200 \mu \mathrm{g} / \mathrm{ml}$ in $10 \mathrm{mM}$ Tris/HCl, $\mathrm{pH} 8.0$, containing $0.5 \mathrm{M}$ $\mathrm{NaCl})$ at $37^{\circ} \mathrm{C}$. Sections were then washed in increasingly stringent solutions of SSC, $2 \times, 1 \times$, and $0.5 \times$ for $5 \mathrm{~min}$ each followed by incubation for $1 \mathrm{~h}$ in $0.1 \times \mathrm{SSC}$ at $65^{\circ} \mathrm{C}$. After rinsing in distilled water, the sections were dehydrated through graded alcohol concentrations and air-dried. For signal detection, slides were apposed to Kodak Biomax MR film (Eastman Kodak, Rochester, NY, USA). Sections were exposed for 1 day for CRH in the paraventricular nucleus of the hypothalamus (PVN), 10 days for $\mathrm{CRH}$ in the central nucleus of the amygdala (CeA), and for 3-4 days for MR and GR probes.

\section{Quantification of the Radioactive Signal}

All data were obtained from the same in situ hybridization experiment. The autoradiograms were digitized (Dage camera, MACII/IMAGE), and the magnitude of the signal from the hybridized ${ }^{35} \mathrm{~S}$-cRNA probe was determined using National Institutes of Health Image software. A macro was written (Dr Serge Campeau, University of Colorado, USA) that enabled the signal above background to be automatically determined. For each section, a background sample was taken over an area of white matter, and the signal threshold was calculated as the mean gray value of background plus $3.5 \mathrm{SD}$. Only pixels that were above the threshold (signal pixels) were used for the densitometric analysis. The 'net' optical density (OD) of these signal pixels was obtained by subtracting the threshold value. To account for small differences in the size of the region sampled, relative OD was expressed as the mean net OD of signal pixels divided by the total number of pixels in the outlined region. The person quantifying was blind to group assignments. CRH mRNA was quantified in the PVN and CeA, and $M R$ and GR mRNA were quantified in the hippocampus. Four hippocampal areas, corresponding to subfields CA1, $\mathrm{CA} 2, \mathrm{CA} 3$, and dentate gyrus (DG), were quantified from a given section. GR mRNA was also quantified in the PVN. OD measurements were taken from the left and right side of two brain sections per animal for each probe and region of interest. A mean value was then generated for each probe and the region of interest to yield one data point per animal for statistical analysis.

\section{Statistical Analysis}

A two-way analysis of variance (ANOVA) was used to determine the effect of treatment and sex on locomotor activity in response to novelty. Fisher's protected least significant difference (PLSD) post hoc analysis followed, with the level of significance set at $P<0.05$.

Group differences in CORT response to novelty and SA behavior were tested using two-way repeated-measures ANOVAs (Group $\times$ Time Point; Group $\times$ Dose, respectively). The number of nose pokes in the active and inactive hole and the number of self-administered infusions were averaged per dose over each 5-day block. Differences due to treatment at a single dose were determined using one-way ANOVAs followed by Bonferroni-corrected $t$-tests. Based on the existing literature (Carroll et al, 2002; Lynch et al, 2000, 2001; Lynch and Carroll, 1999; Sell et al, 2000; Sircar and Kim, 1999) and the locomotor activity data, male and female SA data were analyzed separately.

Given that there is no single, well-accepted criterion defining acquisition of drug SA, we evaluated this behavior using two different indices. First, since the rate of drug SA is dose-dependent, one-way repeated measures ANOVAs were used to determine whether there was an effect of dose for each group. Second, Student's $t$-tests were used to determine whether the number of infusions received at each dose was significantly greater than the average basal rate of response for each group. The basal rate of response was defined as the average number of nose pokes in the inactive hole collapsed across groups and dose, which was equal to 5 . We then used this value (5) to compare drugtaking behavior to general or nonspecific activity at the inactive hole. If a group obtained significantly greater than five infusions per dose, they were considered to have acquired SA behavior. Only values greater than the basal 
rate of response were of interest, thus one-tailed Bonferroni-corrected $t$-tests were used to determine significance.

For each probe and corresponding brain area, a mean value was generated to yield one data point per animal. These data points were averaged per group and compared using one-way ANOVAs followed by Fisher's PLSD post hoc tests. When no group differences were found, data were collapsed across groups to detect differences due to time of early life manipulations. Thus, HAN 1 and SAL 1 (week 1) animals were combined and HAN 2 and SAL 2 (week 2) animals were combined, and both were compared to UND animals.

\section{RESULTS}

\section{Locomotor Activity}

Locomotor activity data are reported as the total number of photocell crossovers recorded during the entire 120-min testing period. Females exhibited greater locomotor activity compared to the males for all treatment groups (effect of sex: $\mathrm{F}=30.60, P<0.0001)$. There was a main effect of Group for both sexes (females: $\mathrm{F}=3.03, P=0.02$; males: $\mathrm{F}=10.34$, $P<0.0001)$. Fisher's post hoc analyses revealed that both male and female animals handled during the second week of life (HAN 2) showed enhanced locomotor response to novelty compared to the other treatment groups (females: $P<0.01$; males: $P \leqslant 0.0001$ - Figure 1 ), suggesting that HAN 2 animals are more exploratory. However, there was only a trend effect for HAN 2 females compared to UND females $(P=0.06)$. In addition, male animals who remained UND were found to be more active than HAN 1 males $(P=0.03)$. There were no additional group differences.

\section{CORT Response to Novelty}

Two-way repeated measures ANOVA revealed no significant group differences in CORT response to novelty (females: $\mathrm{F}=0.69, P=0.61$; males: $\mathrm{F}=0.70, P=0.60$, data not shown).

\section{SA BEHAVIOR}

\section{Females}

Inactive nose pokes. Nose pokes in the inactive hole were assessed as a measure of general activity (nonspecific responding). A two-way repeated measures ANOVA (Group $\times$ Dose) revealed a significant effect of Group $(\mathrm{F}=10.75, P<0.0001)$ and an effect of Dose $(\mathrm{F}=6.87$, $P=0.001$ ) for nose pokes in the inactive hole (data not shown). In support of the locomotor activity data, Bonferroni post hoc analysis indicated that female animals handled during the second week of life (HAN 2) exhibited greater activity at the inactive hole compared to the other groups at $0.125(P \leqslant 0.001)$ and $0.25 \mathrm{mg} / \mathrm{kg}$ per infusion $(P \leqslant 0.002)$. There were no group differences found at the highest dose examined ( $0.5 \mathrm{mg} / \mathrm{kg}$ per infusion). Nose pokes in the inactive hole decreased with increasing dose of drug for the HAN 2 females (see Discussion).

Acquisition of SA. There was a significant effect of dose for the number of infusions obtained for HAN $2(\mathrm{~F}=9.749$,

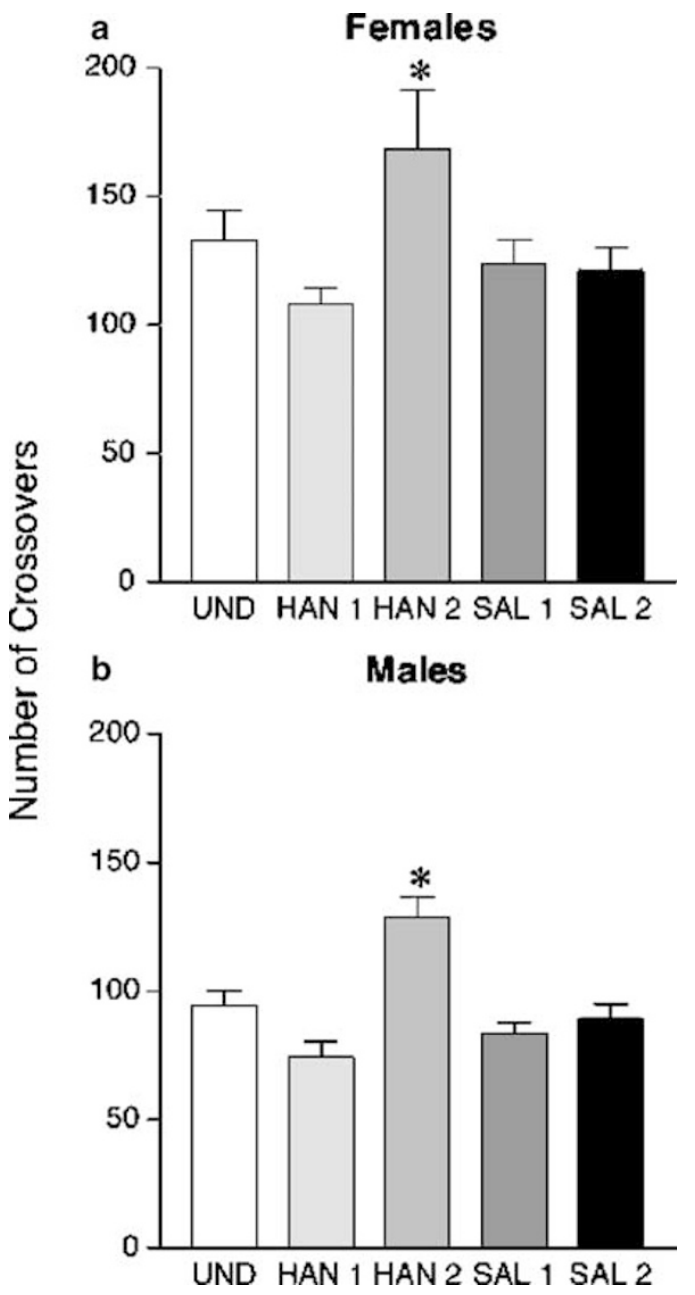

Figure I Locomotor response to novelty in females (a) and males (b). Each vertical bar represents the mean number of photocell crossovers over the total 2-h testing period \pm SE for each group (a) females: UND, $n=32$; HAN I, $n=39$; HAN 2, $n=34$; SAL I, $n=35$; SAL 2, $n=35$; (b) males: UND, $n=37 ;$ HAN I, $n=32 ; \operatorname{HAN} 2, n=33 ; \operatorname{SAL}$ I, $n=31$; SAL 2, $n=33$. Females exhibited greater locomotor activity compared to males in all treatment groups (effect of sex: $F=31.00, P<0.000 I$ ). HAN 2 animals showed enhanced locomotor response to novelty compared to the other treatment groups (a) females, * $P \leqslant 0.06$; (b) males, $* P \leqslant 0.000$ I. Male UND animals were more active than HAN I males $(P<0.05)$.

$P=0.0002)$ and SAL 2 groups $(\mathrm{F}=5.496, P=0.006)$, suggesting that these animals acquired drug-taking behavior. In agreement, Bonferroni-corrected $t$-tests revealed that HAN 2 females acquired drug-taking behavior at the lowest dose examined $(t=4.382, P<0.05)$ and SAL 2 animals acquired $\mathrm{SA}$ at the intermediate dose $(t=3.139$, $P<0.05)$.

Number of infusions. A two-way repeated measures ANOVA revealed an effect of Group $(\mathrm{F}=17.70, P<0.0001)$ and a Group $\times$ Dose interaction $(F=6.83, P<0.0001)$ for the number of infusions obtained. At the lowest dose ( $0.125 \mathrm{mg} / \mathrm{kg} /$ infusion), Bonferroni post hoc analyses indicated that HAN 2 females received a greater number of infusions than all other treatment groups $(P \leqslant 0.004$; Figure $2 \mathrm{a})$. At the intermediate dose $(0.25 \mathrm{mg} / \mathrm{kg} /$ infusion $)$, both HAN 2 and SAL 2 females received more infusions 
than all other groups $(P \leqslant 0.001$; Figure $2 \mathrm{a})$. SAL 2 animals continued to increase their rate of response compared to all other groups $(P<0.0001$; Figure $2 \mathrm{a})$ at the highest dose, whereas the HAN 2 group decreased their rate of response. In support of these data, HAN 2 and SAL 2 females were found to differ significantly from the other treatment groups when individual group comparisons were made

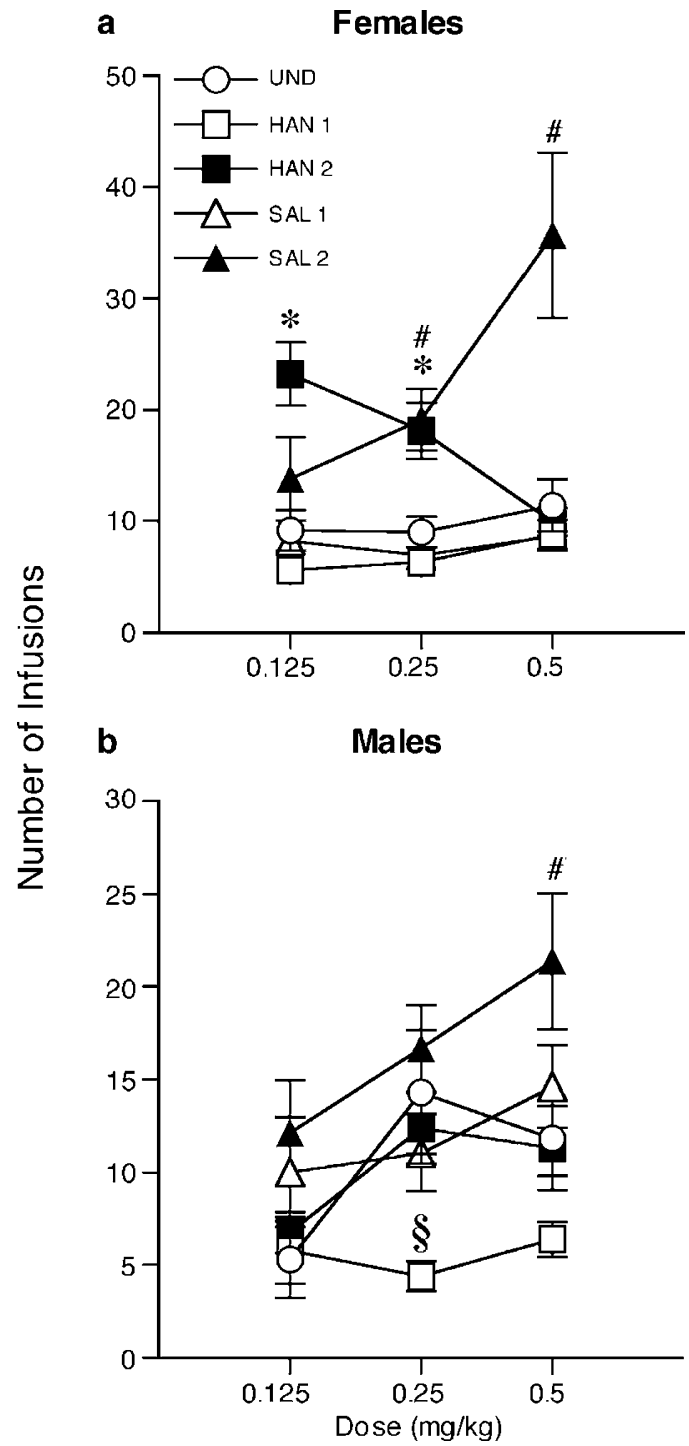

Figure 2 SA behavior in females (a) and males (b). Each data point represents the mean number of infusions obtained per dose \pm SE for each group (a) females: UND, $n=8 ; \operatorname{HAN~I,~} n=10 ; \operatorname{HAN~2,} n=8$; SAL ।, $n=10$; SAL 2, $n=8$; (b) males: UND, $n=10$; HAN I, $n=8$; HAN 2, $n=8$; SAL I, $n=9$; SAL 2, $n=10$. (a) HAN 2 and SAL 2 females were found to differ significantly from the other treatment groups $(P<0.05)$. HAN 2 female rats showed greater cocaine intake than the other groups at the lowest and intermediate doses (*P $\leqslant 0.004$ ), while SAL 2 animals exhibited increased drug-taking behavior at the intermediate and highest doses examined $\left({ }^{P} P \leqslant 0.00 I\right)$. (b) Male SAL 2 animals were found to differ significantly from the other treatment groups $(P<0.05)$. SAL 2 males showed greater cocaine intake at the highest dose examined compared to HAN I animals $\left.{ }^{\#} P<0.000 \mid\right)$. HAN I males were found to differ significantly from the other treatment groups $(P<0.05)$. HAN I males received fewer infusions than SAL 2 or UND animals at $0.25 \mathrm{mg} / \mathrm{kg} /$ infusion $\left({ }^{\S} p<0.001\right)$. using two-way repeated measures ANOVAs across doses $(P<0.05)$.

\section{Males}

Inactive nose pokes. There were no significant group differences in nose pokes in the inactive hole for male animals (data not shown).

Acquisition of SA. There was a significant effect of dose for the number of infusions obtained for the UND $(F=5.134$, $P=0.008)$ and HAN 2 males $(\mathrm{F}=3.5, P=0.04)$, and a trend towards significance for the SAL $1(\mathrm{~F}=2.96, P=0.06)$ and SAL 2 males $(\mathrm{F}=2.584, P=0.08)$. Using the second criterion for acquisition, however, Bonferroni-corrected $t$-tests revealed that SAL 2 animals were the only group to approach significance for acquisition of drug-taking behavior. This effect was seen at the intermediate dose $(0.25 \mathrm{mg} /$ $\mathrm{kg} /$ infusion $)(t=2.664, P<0.05)$.

Number of infusions. A two-way repeated measures ANOVA (Group $\times$ Dose) revealed a significant effect of Group $(\mathrm{F}=5.301, \quad P=0.0004)$ and an effect of Dose $(\mathrm{F}=8.449, \quad P=0.0003) \quad$ for the number of infusions obtained. There was no effect of group at the lowest dose examined. At the intermediate dose, Bonferroni post hoc analyses indicated that HAN 1 males received fewer infusions than SAL 2 or UND animals $(P<0.001)$. SAL 2 males continued to receive a greater number of infusions than all the other treatment groups at the highest dose $(0.5 \mathrm{mg} / \mathrm{kg} /$ infusion $)$, but this effect reached significance only when compared to the HAN 1 animals $(P<0.0001$; Figure $2 \mathrm{~b}$ ). SAL 2 males were also found to significantly differ from the other treatment groups when individual group comparisons were made using two-way repeated measures ANOVAs across doses $(P<0.05)$. The number of infusions for HAN 1 males was significantly lower than all the other treatment groups (HAN 1 vs: $\mathrm{UND}, \mathrm{F}=4.9$; HAN $2, \mathrm{~F}=8.6$; SAL 1, $\mathrm{F}=6.8 ; \mathrm{SAL} 2, \mathrm{~F}=25.3 ; P<0.05)$.

In situ hybridization histochemistry. Six female brains were examined using in situ hybridization histochemistry. There were no group differences in basal CRH mRNA expression in the PVN or CeA (data not shown). In addition, no differences were detected in the amount of basal MR mRNA expression in any hippocampal field (ie CA1, CA2, CA3, and DG-data not shown). There was a Group effect for GR mRNA expression in the DG $(F=3.015$, $P=0.037)$ and a trend towards significance in the CA1 region $(\mathrm{F}=2.388, P=0.078)$. In the DG, HAN 2 and SAL 2 animals had lower levels of GR mRNA compared to SAL 1 animals $(P \leqslant 0.02$; Figure 3a). Relative to UND animals, HAN 2 rats expressed lower levels of GR mRNA in the DG $(P \leqslant 0.03)$ and SAL 2 animals showed a similar trend $(P \leqslant 0.08)$. Given that there were no differences in treatment found within a given week, animals manipulated during week 1 (HAN 1 and SAL 1) were combined and compared to animals manipulated during week 2 (HAN 2 and SAL 2). These groups (week 1 and week 2) were then compared to UND animals. There was a significant effect of week for GR mRNA expression in CA1 $(\mathrm{F}=4.75, P=0.017)$ and in the 


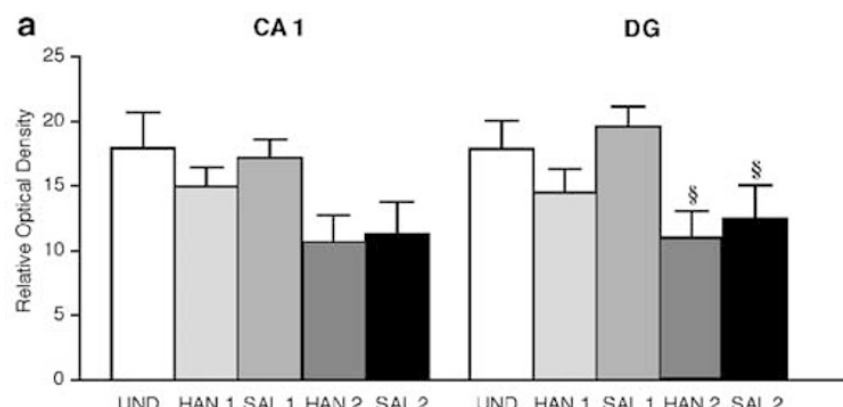

b

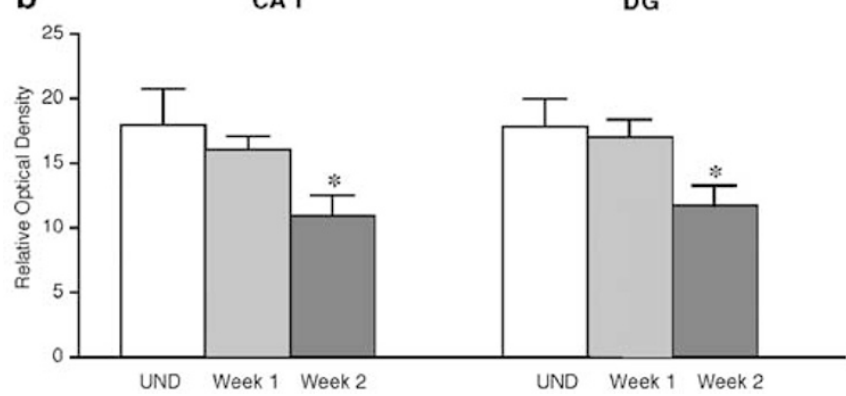

Figure 3 Relative OD of GR mRNA expression in CAI and DG fields of the hippocampus in female rats. Each data point represents the mean value of relative OD units \pm SE for each group (a) (UND, $n=6$; HAN I, $n=6$; SAL I, $n=6$; HAN 2, $n=6$; SAL 2, $n=6$ ) or for combined groups based on time of early life manipulation (b) (UND, $n=6$; week $1, n=12$; week 2 , $n=12$ ). (a) There was a Group effect for GR mRNA expression in the DG $(P=0.04)$ and a trend towards significance in the $C A I$ region $(P=0.08)$. HAN 2 and SAL 2 animals had lower levels of GR mRNA compared to SAL I animals in the DG $(\$ p \leqslant 0.02)$. (b) There was a significant effect of week for GR mRNA expression in CAI and in the DG. Relative to UND animals and those manipulated in week I, animals manipulated during the second week of life exhibited lower levels of GR mRNA expression in CAI $(* P \leqslant 0.02)$ and in the DG $(* P \leqslant 0.03)$ of the hippocampus.

DG $(\mathrm{F}=4.216, P=0.025)$. In agreement with our SA data, animals manipulated during week 2 of life were significantly different from animals manipulated in week 1 and from UND animals. Specifically, those manipulated during the second week of life exhibited lower levels of GR mRNA expression in the CA1 $(P \leqslant 0.02)$ and in the DG $(P \leqslant 0.03)$ of the hippocampus (Figure $3 \mathrm{~b}$ ). There were no differences in GR mRNA expression in the PVN.

\section{DISCUSSION}

We investigated the effects of early life manipulations on the vulnerability to drug-taking behavior in adulthood. Specifically, we compared the effects of daily s.c. saline injections and handling during week 1 vs week 2 of life on the propensity to acquire cocaine SA in adulthood. Rats manipulated during the second week of life more readily acquired cocaine SA compared to animals treated during the first week of life or those who remained undisturbed throughout the first 2 weeks of life. Within the second-week time frame, however, both the quality of the stimulus and gender proved to be important. In females, both handling and saline injections administered during the second week of life facilitated SA behavior, although handling produced a greater effect (Figure 2a). This suggests that, of the groups tested, HAN 2 females were the most sensitive to the reinforcing effects of cocaine. The male data were more variable than the female data, but it appeared that the SAL 2 males exhibited enhanced sensitivity to the drug. Males receiving saline injections during the second week of life showed increased SA behavior at the two highest doses of cocaine examined. Taken together, these findings suggest that the sex of the animal and the timing and type of manipulations that occur early in life are important factors in predicting vulnerability to drug-taking behavior.

Although studies suggest that female rats have a greater locomotor response to psychostimulants (Savageau and Beatty, 1981; Schneider and Norton, 1979) and are more sensitive to the reinforcing effects of cocaine (Roberts et al, 1989), few studies have compared female drug SA (i.v.) to that of males (Haney et al, 1995; Matthews et al, 1999). On the whole, it appears that a greater percentage of female rats acquire SA, and at a faster rate than males (Carroll et al, 2002; Lynch et al, 2000, 2001; Lynch and Carroll, 1999; Matthews et al, 1999). In support of the literature, the present study shows that females in general exhibited increased drug-taking behavior compared to the males. There were also differences in the pattern of drug-taking behavior (Figure 2) and the amount of variance inherent in the behavior of each sex. It is important to recognize the sex differences in the present study, but due to the large amount of variance in the male SA behavior and the difficulty with interpreting the data, the remainder of this discussion will focus on the females.

Female animals manipulated during the first week of life were more 'resistant' or less sensitive to cocaine SA in adulthood. At the doses examined, females who were handled or injected during the first week of life (HAN 1 and SAL 1) were the least likely to self-administer cocaine (Figure 2a). In contrast, both handling and injection stress administered during the second week of life (HAN 2 and SAL 2) facilitated SA behavior (Figure 2a). These findings suggest that the age of manipulation early in life is critical in determining long-term outcomes, especially for drug-taking behavior.

Although we did not examine maternal behavior in the present study, our findings are consistent with the hypothesis that peak maternal care during the first week of life 'protected' those animals treated during this period from drug-taking behavior in adulthood. Natural maternal behavior peaks during the first part of the lactation period (PND 1-7) and tapers off towards weaning (PND 21) (Reisbick et al, 1975; Rosenblatt, 1969; Rosenblatt and Lehrman, 1963). Thus, one would expect that perturbation of the litter during the first week of life would elicit greater maternal care than perturbation during the second week of life.

It has been demonstrated (predominantly in male animals) that the first week of life is the 'critical' period for eliciting the handling effect on emotional and neuroendocrine responses in adulthood (Levine and Lewis, 1959; Meaney and Aitken, 1985). Early handling has been shown to alter the behavior and physiology of rat pups, and this in turn heightens maternal sensitivity. In particular, increases in vocalizations and decreases in body temperature that result from handling are thought to induce maternal 
behavior (Brunelli et al, 1994; Stern, 1997). Specifically, handling-induced increases in licking and grooming on the first 10 days of life have been found to be 'protective', resulting in decreased LHPA responsivity and behavioral reactivity to stress in adulthood (Ader, 1969; Hess et al, 1969; Levine, 1967; Meaney and Aitken, 1985; Meaney et al, 1989; Viau et al, 1993). We speculate that in the present study, increased maternal care during the first week of life protected those animals manipulated during this period, regardless of treatment.

The quality of the stimulus during the second week of life proved to be important in determining subsequent behavior. Female animals who were handled during the second week of life (HAN 2) were the most sensitive to cocaine, exhibiting increased drug-taking behavior at the lowest dose tested $(0.125 \mathrm{mg} / \mathrm{kg} /$ infusion $)$. The shapes of the doseresponse curves (Figure 2a) further suggest that the HAN 2 females were the most sensitive to the reinforcing effects of the drug. HAN 2 animals appear to be on the descending limb of the classical inverted U-shaped curve over the entire range of doses tested, while SAL 2 animals seem to be on the ascending limb of the dose-response function. This suggests that HAN 2 females were more sensitive to the reinforcing effects of cocaine than SAL 2 animals, but compared to all other groups, both of these groups were more sensitive to the drug.

As alluded to above, rodent young are not passive recipients of maternal care, but provide cues that elicit mother-pup interactions (Moltz and Leon, 1973; Reisbick et al, 1975; Smotherman et al, 1974). In fact, the rodent dam is sensitive to the changing stimulus qualities of the pups (Meier and Schutzman, 1968; Young, 1965) and shows systematic changes in maternal behavior depending on the nature of the treatment that the offspring have received (Barnett and Burn, 1967; Bell et al, 1974) and the time during lactation in which the manipulations occur (Smotherman et al, 1977a,b). It has been demonstrated that heightened maternal behavior results from pup cues elicited by more intense treatments such as electric shock (0.4 mA) (Smotherman et al, 1977a, b). In fact, mothers respond more to shocked than to handled pups when these manipulations are performed during the second week of life (Smotherman et al, 1977a,b). When these treatments are performed during the first week of life, however, shocked and handled animals receive equal amounts of attention (Smotherman et al, 1977a). To interpret our female data, we speculate that differential maternal behavior during the second week of life might have contributed to the group differences seen in the SA behavior of those animals treated during this period (HAN 2 and SAL 2).

Handling during the second week of life also resulted in increased locomotor activity compared to all other groups. Piazza has demonstrated (predominantly in male animals) that one can predict the drug-taking behavior of a rodent based on its endocrine and locomotor reactivity profile (Piazza et al, 1989, 1990, 1998, 1991). For example, animals with a relatively high locomotor and CORT response to novelty are more likely to initiate psychostimulant SA (Piazza et al, 1990, 1998, 1991). In terms of adrenocortical responsivity, these predictions did not hold true for the present study. Despite the fact that female HAN 2 rats exhibited increased locomotor activity in response to novelty and enhanced sensitivity to the reinforcing effects of cocaine, there were no group differences in CORT response to novelty.

The apparent lack of differences in CORT responsivity in the present study may be explained in a number of ways. First, there are some discrepancies in the literature associating LHPA responsivity and drug-taking behavior. While Piazza and Le Moal (1998) and Goeders (1997) have suggested that enhanced sensitivity to the reinforcing effects of cocaine is related to high CORT levels, others report an inverse relationship between adrenocortical responsivity and drug-taking behavior in rodents (Deroche et al, 1997; Kosten et al, 1997, 2000). Second, adrenocortical responsivity varies considerably depending on the manipulations performed early in life as well as on the type and length of the stressor imposed at the time of testing (Nunez et al, 1996; Ogawa et al, 1994). Had we administered a different type of stressor to elicit a response in adulthood, we might have been able to detect group differences in CORT levels.

Although there were no apparent differences in adrenocortical response to novelty in the present study, decreased levels of GR mRNA in the hippocampus suggest that female animals manipulated during the second week of life may have an impaired negative feedback system or a hyperresponsive LHPA axis in response to other stressors. Low levels of hippocampal GR expression typically reflect decreased negative feedback sensitivity, or increased pituitary-adrenal activity (deKloet, 1991; Jacobson and Sapolsky, 1991). For example, rats subjected to $180-\mathrm{min}$ maternal separation daily for the first two weeks of life show decreased GR expression in the hippocampus and increased LHPA responses to stress (Ladd et al, 2000; Meaney et al, 2002). Likewise, high-responding rats (HR), who are used as an animal model of novelty-seeking behavior, have decreased expression of hippocampal GR mRNA (Kabbaj et al, 2000), and exhibit a prolonged CORT response to novelty relative to their low-responding (LR) counterparts (Dellu et al, 1996; Hooks et al, 1991; Piazza et al, 1989). Interestingly, both $\mathrm{HR}$ rats and rats subjected to $180-\mathrm{min}$ maternal separation also show greater stress- and/or druginduced elevations of mesolimbic dopamine neurotransmission and increased sensitivity to the psychomotor-activating effects of cocaine (Hooks et al, 1991; Meaney et al, 2002 cf.; Li et al, 2003).

Glucocorticoids regulate the mesolimbic dopaminergic system, increasing dopamine release in the nucleus accumbens and increasing the propensity to self-administer psychostimulants (Piazza and Le Moal, 1996). Thus, decreased expression of hippocampal GR could enhance the reinforcing efficacy of drugs of abuse by further elevating glucocorticoid levels (Kabbaj et al, 2000). Our findings are consistent with the literature in that those (female) animals who had decreased GR mRNA in the hippocampus exhibited increases in drug-taking behavior.

The mesolimbic dopaminergic system makes up the reward circuitry of the brain and is essential to the acquisition of psychostimulant administration (Deminiere et al, 1988; Wise, 1989). Like the LHPA axis, this system undergoes significant developmental changes postnatally (Cabib et al, 1993; Gariepy et al, 2002; Kehoe et al, 1998a). Few studies have examined the interaction between early life events, LHPA reactivity, and the dopaminergic system. 
de Kloet et al (1996) reported that genetic selection of rats for differences in dopamine responsiveness coselects for adrenocortical responsivity to ACTH and corticosteroid feedback efficacy. Differences in dopamine responsiveness were postulated to be secondary to developmental changes in the LHPA axis. Similar to our animals, there were no differences in CORT response to novelty between the two lines of rats used in de Kloet's studies. Thus, despite our lack of differences in peripheral measures of LHPA responsivity, we speculate that the increased vulnerability to drug-use observed in animals manipulated during the second week of life is related to specific effects on LHPA development, namely alterations of hippocampal GR expression, and subsequent interactions with the dopaminergic system.

It is important to note that we cannot exclude other possible explanations for the group differences in drugtaking behavior displayed in the present study. For example, differences in learning ability cannot be ruled out when interpreting the SA data presented here. The animals used in this study were not trained to acquire operant responding prior to the SA paradigm. However, the enhanced acquisition and dose-effect patterns exhibited by animals manipulated during the second week of life suggest that these animals are responding to the reinforcing effects of the drug rather than exhibiting a nonspecific effect of learning. We must also consider that the SA behavior of HAN 2 females might be due to group differences in general activity levels. HAN 2 females showed enhanced activity at the 'inactive' hole during the SA paradigm. It is unclear whether this activity at the 'inactive' hole was due to the locomotor-activating effects of cocaine or generalized motor activity. The effect of dose for HAN 2 females, both in terms of the number of infusions obtained (Figure 2) and in terms of the number of nose pokes in the inactive hole (data not shown), suggests that the psychomotor effects of the drug may have played a role in their activity at the inactive hole. Regardless of the cause, the reported differences in locomotor activity highlight the involvement of the mesolimbic dopamine system in the behavioral phenotypes of these animals.

\section{SUMMARY}

Many studies have demonstrated that dramatic and sustained neurobiological changes take place during the neonatal period, and that these changes have consequences on LHPA axis function, dopaminergic activity, and behavioral responsiveness throughout the life of the animal. The exact timing of a stressor, the regimen of exposure, and the resulting maternal behavior elicited by early life intervention appear to be critical in determining LHPA function in adulthood and individual vulnerability to substance abuse. Although the early life manipulations used in the present study did not affect adrenocortical response to novelty, we did detect differences in basal hippocampal GR expression. Our findings indicate that differences in basal hippocampal GR expression might contribute to individual differences in the propensity to use drugs. However, there are, unquestionably, a myriad of factors contributing to individual vulnerability, and a more detailed neurobiological profile will be necessary to further delineate group differences and pinpoint neurochemical phenotypes associated with drugtaking behavior. Nonetheless, the present study suggests that the second week of life in the rodent is a critical time period for eliciting long-term changes in the propensity to self-administer drugs. Further, the intensity of the stimulus within that time frame and the sex of the animal appear to be key factors in determining long-term outcomes.

\section{ACKNOWLEDGEMENTS}

This research was funded by the National Institute of Drug Abuse (NIDA) grants awarded to SBF (DA06073), DMV (DA11455), and TER (R37 DA04294). TER was also supported by an NIDA Senior Scientist Award (K05 DA00473). We thank members of the Robinson and Vazquez laboratories, especially Charles Bailey, Asha Patil, and Shannon Weger for their technical assistance.

\section{REFERENCES}

Ader R (1969). Early experiences accelerate maturation of the 24hour adrenocortical rhythm. Science 163: 1225-1226.

Barnett SA, Burn J (1967). Early stimulation and maternal behaviour. Nature 213: 150-152.

Bell RW, Nitschke W, Bell NJ, Zachman TA (1974). Early experience, ultrasonic vocalizations, and maternal responsiveness in rats. Dev Psychobiol 7: 235-242.

Browman KE, Badiani A, Robinson TE (1998). The influence of environment on the induction of sensitization to the psychomotor activating effects of intravenous cocaine in rats is dosedependent. Psychopharmacology 137: 90-98.

Brunelli SA, Shair HN, Hofer MA (1994). Hypothermic vocalizations of rat pups (Rattus norvegicus) elicit and direct maternal search behavior. J Comp Psychol 108: 298-303.

Cabib S, Puglisi-Allegra S, D'Amato FR (1993). Effects of postnatal stress on dopamine mesolimbic system responses to aversive experiences in adult life. Brain Res 604: 232-239.

Campbell J, Spear LP (1999). Effects of early handling on amphetamine-induced locomotor activation and conditioned place preference in the adult rat. Psychopharmacology 143: 183-189.

Caine SB, Lintz R, Koob GF (1993). Intravenous drug selfadministration techniques in animals. In Behavioral Neuroscience, a practical approach. New York, Oxford. pp. 117-143.

Carroll ME, Morgan AD, Lynch WJ, Campbell UC, Dess NK (2002). Intravenous cocaine and heroin self-administration in rats selectively bred for differential saccharin intake: phenotype and sex differences. Psychopharmacology (Berl) 161: 304-313.

Colvin GB, Sawyer CH (1969). Induction of running activity by intracerebral implants of estrogen in ovariectomized rats. Neuroendocrinology 4: 309-320.

Crombag HS, Badiani A, Robinson TE (1996). Signalled versus unsignalled intravenous amphetamine: large differences in the acute psychomotor response and sensitization. Brain Res 722: 227-231.

de Kloet ER (1991). Brain corticosteroid receptor balance and homeostatic control. Front Neuroendocrinol 12: 95-164.

deKloet ER, Rots NY, Cools AR (1996). Brain-corticosteroid hormone dialogue: slow and persistent. Cell Mol Neurobiol 16: 345-355.

Dellu F, Piazza PV, Mayo W, Le Moal M, Simon H (1996). Noveltyseeking in rats-biobehavioral characteristics and possible relationship with the sensation-seeking trait in man. Neuropsychobiology 34: 136-145. 
Deminiere JM, Taghzouti K, Tassin JP, Le Moal M, Simon H (1988). Increased sensitivity to amphetamine and facilitation of amphetamine self-administration after 6-hydroxydopamine lesions of the amygdala. Psychopharmacology 94: 232-236.

Denenberg VH, Bell RB (1960). Critical periods for the effects of infantile experience on adult learning. Science 131: 227-228.

Denenberg VH, Zarrow MX (1971). Effects of handling in infancy upon adult behavior and adrenocortical activity: suggestions for a neuroendocrine mechanism. In: Walcher DN, Peters DL (eds) Early Childhood: The Development of Self-Regulatory Mechanisms. Academic Press: New York. pp 40-74.

Dent GW, Smith MA, Levine S (2000). Rapid induction of corticotropin-releasing hormone gene transcription in the paraventricular nucleus of the developing rat. Endocrinology 141: $1593-1598$.

Deroche V, Caine SB, Heyser CJ, Polis I, Koob GF, Gold LH (1997). Differences in the liability to self-administer intravenous cocaine between C57BL/6 $\times$ SJL and BALB/cByJ mice. Pharmacol Biochem Behav 57: 429-440.

Dinwiddie SH, Reich T, Cloninger CR (1992). Prediction of intravenous drug use. Comp Psychiatry 33: 173-179.

Duncan DF (1977). Life stress as a precursor to adolescent drug dependence. Int J Addict 12: 1047-1056.

Enoch MA, Goldman D (1999). Genetics of alcoholism and substance abuse. Psychiatr Clin North Am 22: 289-299.

Gariepy J-L, Rodriguiz RM, Jones BC (2002). Handling, genetic and housing effects on the mouse stress system, dopamine function, and behavior. Pharmacol Biochem Behav 73: 7-17.

Goeders NE (1997). A neuroendocrine role in cocaine reinforcement. Psychoneuroendocrinology 22: 237-259.

Gordon HW (2002). Early environmental stress and biological vulnerability to drug abuse. Psychoneuroendocrinology 27: 115-126.

Grota LJ, Ader R (1969). Continuous recording of maternal behavior in Rattus norvegicus. Anim Behav 17: 722-729.

Grota LJ, Ader R (1974). Behavior of lactating rats in a dualchambered maternity cage. Horm Behav 5: 275-282.

Guteirres SE, Molof M, Ungerleider S (1994). Relationship of 'risk' factors to teen substance use: a comparison of abstainers, infrequent users, and frequent users. Int J Addict 29: 1559-1579.

Haney M, Maccari S, Le Moal M, Simon H, Piazza PV (1995). Social stress increases the acquisition of cocaine self-administration in male and female rats. Brain Res 698: 46-52.

Herman JP, Patel PD, Akil H, Watson SJ (1989). Localization and regulation of glucocorticoid and mineralocorticoid receptor messenger RNAs in the hippocampal formation of the rat. Mol Endocrinol 3: 1886-1894.

Hess JL, Denenberg VH, Zarrow MX, Pfeifer WD (1969). Modification of the corticosterone response curve as a function of handling in infancy. Physiol Behav 4: 109-112.

Higley JD, Bennett AJ (1999). Central nervous system serotonin and personality as variables contributing to excessive alcohol consumption in non-human primates. Alcohol 34: 402-418.

Higley JD, Hasert MF, Suomi SJ, Linnoila M (1991). Nonhuman primate model of alcohol abuse: effects of early experience, personality, and stress on alcohol consumption. Proc Natl Acad Sci USA 88: 7261-7265.

Hooks MS, Jones GH, Smith AD, Neill DB, Justice Jr JB (1991). Response to novelty predicts the locomotor and nucleus accumbens dopamine response to cocaine. Synapse 9: 121-128.

Huot RL, Thrivikraman V, Meaney MJ, Plotsky PM (2001). Development of adult ethanol preference and anxiety as a consequence of neonatal maternal separation in Long Evans rats and reversal with antidepressant treatment. Psychopharmacology (Berl) 158: 366-373.

Jacobson L, Sapolsky R (1991). The role of the hippocampus in feedback regulation of the hypothalamic-pituitary-adrenocortical axis. Endocr Rev 12: 118-134.
Kabbaj M, Devine DP, Savage VR, Akil H (2000). Neurobiological correlates of individual differences in novelty-seeking behavior in the rat: differential expression of stress-related molecules. $J$ Neurosci 20: 6983-6988.

Kehoe P, Shoemaker WJ, Arons C, Triano L, Suresh G (1998a). Repeated isolation stress in the neonatal rat: relation to brain dopamine systems in the 10-day-old rat. Behav Neurosci 112: 1466-1474.

Kehoe P, Shoemaker WJ, Triano L, Callahan M, Rappolt G (1998b). Adult rats stressed as neonates show exaggerated behavioral responses to both pharmacological and environmental challenges. Behav Neurosci 112: 116-125.

Kehoe P, Shoemaker WJ, Triano L, Hoffman J, Arons C (1996). Repeated isolation in the neonatal rat produces alterations in behavior and ventral striatal dopamine release in the juvenile after amphetamine challenge. Behav Neurosci 110: 1435-1444.

Kosten TA, Miserendino MJ, Haile CN, deCaprio JL, Jatlow PI, Nestler EJ (1997). Acquisition and maintenance of intravenous cocaine self-administration in Lewis and Fischer inbred rat strains. Brain Res 778: 418-429.

Kosten TA, Miserendino MJD, Kehoe P (2000). Enhanced acquisition of cocaine self-administration in adult rats with neonatal isolation stress experience. Brain Res 875: 44-50.

Ladd CO, Huot RL, Thrivikraman KV, Nemeroff CB, Meaney MJ, Plotsky PM (2000). Long-term behavioral and neuroendocrine adaptations to adverse early experience. Prog Brain Res 122: 81-103.

Levine S (1967). Maternal and environmental influences on the adrenocortical response to stress in weanling rats. Science 156: 258-260.

Levine S (1975). The potential influence of infantile stimulation on emotional disorders. In: Levi L (ed) Society, Stress and Disease. Oxford Univ Press: London. pp 411-415.

Levine S, Lewis GW (1959). Critical period for effects of infantile experience on maturation of stress response. Science 129: 42-43.

Li Y, Robinson TE, Bhatnagar S (2003). Effects of maternal separation on behavioural sensitization produced by repeated cocaine administration in adulthood. Brain Res 960: 42-47.

Lynch WJ, Arizzi MN, Carroll ME (2000). Effects of sex and the estrous cycle on regulation of intravenously self-administered cocaine in rats. Psychopharmacology 152: 132-139.

Lynch WJ, Carroll ME (1999). Sex differences in the acquisition of intravenously self-administered cocaine and heroin in rats. Psychopharmacology 144: 77-82.

Lynch WJ, Roth ME, Mickelberg JL, Carroll ME (2001). Role of estrogen in the acquisition of intravenously self-administered cocaine in female rats. Pharmacol Biochem Behav 68: 641-646.

Marinelli M, White FJ (2000). Enhanced vulnerability to cocaine self-administration is associated with elevated impulse activity of midbrain dopamine neurons. J Neurosci 20: 8876-8885.

Matthews K, Robbins TW, Everitt BJ, Caine SB (1999). Repeated neonatal maternal separation alters intravenous cocaine selfadministration in adult rats. Psychopharmacology 141: 123-134.

Meaney MJ, Aitken DH (1985). The effects of early postnatal handling on hippocampal glucocorticoid receptor concentrations: temporal parameters. Brain Res 354: 301-304.

Meaney MJ, Aitken DH, Viau V, Sharma S, Sarrieau A (1989). Neonatal handling alters adrenocortical negative feedback sensitivity and hippocampal type II glucocorticoid receptor binding in the rat. Neuroendocrinology 50: 597-604.

Meaney MJ, Brake W, Gratton A (2002). Environmental regulation of the development of mesolimbic dopamine systems: a neurobiological mechanism for vulnerability to drug abuse? Psychoneuroendocrinology 27: 127-138.

Meier GW, Schutzman LH (1968). Mother-infant interactions and experimental manipulation: confounding or misidentification? Dev Psychobiol 1: 141-145. 
Moltz H, Leon M (1973). Stimulus control of the maternal pheromone in the lactating rat. Physiol Behav 10: 69-71.

Moss HB, Vanyukov M, Yao JK, Kirillova GP (1999). Salivary cortisol responses in prepubertal boys: the effects of parental substance abuse and association with drug use behavior during adolescence. Biol Psychiatry 45: 1293-1299.

Nestler EJ (2000). Genes and addiction. Nat Genet 26: 277-281.

Nunez JF, Ferre P, Escorihuela RM, Tobena A, Fernandez-Teruel A (1996). Effects of postnatal handling of rats on emotional, HPAaxis, and prolactin reactivity to novelty and conflict. Physiol Behav 60: 1355-1359.

O'Brien CP, Ehrman RN, Terns IN (1986). In: Goldeberg SR, Stolerman IP (eds) Behavioral Analysis of Drug Dependence. Academic Press: Orlando, 329 pp.

Ogawa T, Mikuni M, Kuroda Y, Muneoka K, Mori KJ, Takahashi K (1994). Periodic maternal deprivation alters stress response in adult offspring: potentiates the negative feedback regulation of restraint stress-induced adrenocortical response and reduces the frequencies of open field-induced behaviors. Pharmacol Biochem Behav 49: 961-967.

Patel P, Sherman T, Goldman D, Watson S (1989). Molecular cloning of a mineralocorticoid receptor cDNA from rat hippocampus. Mol Endocrinol 3: 1877-1885.

Piazza PV, Deminiere JM, Le Moal M, Simon H (1989). Factors that predict individual vulnerability to amphetamine self-administration. Science 245: 1511-1513.

Piazza PV, Deminiere JM, Maccari S, Mormede P, Le Moal M, Simon H (1990). Individual reactivity to novelty predicts probability of amphetamine self-administration. Behav Pharmacol 1: 339-345.

Piazza PV, Deroche V, Rouge-Pont F, Le Moal M (1998). Behavioral and biological factors associated with individual vulnerability to psychostimulant abuse. NIDA Res Monogr 169: 105-133.

Piazza PV, Le Moal M (1998). The role of stress in drug selfadministration. Trends Pharmacol Sci 19: 67-74.

Piazza PV, Le Moal ML (1996). Pathophysiological basis of vulnerability to drug abuse: role of an interaction between stress, glucocorticoids, and dopaminergic neurons. Annu Rev Pharmacol Toxicol 36: 359-378.

Piazza PV, Maccari S, Deminiere JM, Le Moal M, Mormede P, Simon H (1991). Corticosterone levels determine individual vulnerability to amphetamine self-administration. Proc Natl Acad Sci USA 88: 2088-2092.

Reisbick S, Rosenblatt JS, Mayer AD (1975). Decline of maternal behavior in the virgin and lactating rat. J Comp Physiol Psychol 89: 685-700.

Roberts DCS, Bennett SAL, Vickers GJ (1989). The oestrous cycle affects cocaine self-administration on a progressive ratio schedule in rats. Psychopharmacology 98: 408-411.

Robinson TE, Gorny G, Mitton E, Kolb B (2001). Cocaine selfadministration alters the morphology of dendrites and dendritic spines in the nucleus accumbens and neocortex. Synapse 39: 257-266.

Rosenblatt JS (1969). The development of maternal responsiveness in the rat. Am J Orthopsychiatry 39: 36-56.

Rosenblatt JS, Lehrman DS (1963). Maternal behavior of the laboratory rat. In: Rheingold HL (ed) Maternal Behavior in Mammals. Wiley: New York. pp 8-57.
Russell PA (1971). Infantile stimulation in rodents: a consideration of possible mechanisms. Psychol Bull 75: 192-202.

Savageau MM, Beatty WW (1981). Gonadectomy and sex differences in the behavioural response to amphetamine and apomorphine in rats. Pharmacol Biochem Behav 14: 17-21.

Schneider BF, Norton S (1979). Circadian and sex differences in hyperactivity produced by amphetamine in rats. Physiol Behav 22: $47-51$

Sell SL, Scalzitti JM, Thomas ML, Cunningham KA (2000). Influence of ovarian hormones and estrous cycle on the behavioral response to cocaine in female rats. J Pharmacol Exp Ther 293: 879-886.

Sircar R, Kim D (1999). Female gonadal hormones differentially modulate cocaine-induced behavioral sensitization in Fischer, Lewis, and Sprague-Dawley rats. J Pharmacol Exp Ther 289: $54-65$.

Slob AK, Bogers H, van Stolk MA (1981). Effects of gonadectomy and exogenous gonadal steroids on sex differences in open field behaviour of adult rats. Behav Brain Res 2: 347-362.

Smith MA, Kim S-Y, Van Oers HJJ, Levine S (1997). Maternal deprivation and stress induce immediate early genes in the infant rat brain. Endocrinology 138: 4622-4628.

Smotherman WP, Bell RW, Starzec J, Elias J, Zachman TA (1974). Maternal responses to infant vocalizations and olfactory cues in rats and mice. Behav Biol 12: 55-66.

Smotherman WP, Brown CP, Levine S (1977a). Maternal responsiveness following differential pup treatment and mother-pup interactions. Horm Behav 8: 242-253.

Smotherman WP, Wiener SG, Mendoza SP, Levine S (1977b). Maternal pituitary-adrenal responsiveness as a function of differential treatment of rat pups. Dev Psychobiol 10: 113-122.

Stern JM (1997). Offspring-induced nurturance: animal-human parallels. Dev Psychobiol 31: 19-37.

Tarter R, Vanyukov M, Giancola P, Dawes M, Blackson T, Mezzich A et al (1999). Etiology of early age onset substance use disorder: a maturational perspective. Dev Psychopathol 11: 657-683.

Vazquez DM, Eskandari R, Zimmer CA, Levine S, Lopez JF (2002). Brain 5-HT receptor system in the stressed infant rat: implications for vulnerability to substance abuse. Psychoneuroendocrinology 27: 245-272.

Viau V, Sharma S, Plotsky PM, Meaney MJ (1993). Increased plasma ACTH responses to stress in nonhandled compared with handled rats require basal levels of corticosterone and are associated with increased levels of ACTH secretagogues in the median eminence. J Neurosci 13: 1097-1105.

Wagner FA, Anthony JC (2002). From first drug use to drug dependence; developmental periods of risk for dependence upon marijuana, cocaine, and alcohol. Neuropsychopharmacology 26: $479-488$

Wang G (1923). The relation between spontaneous activity and the oestrous cycle in the rat. Comp Phsychol Monogr 2, Serial 6.

Weeks JR (1972). Long-term intravenous infusions. In: Myers RD (ed) Methods in Psychobiology. Academic Press: London. pp 155-168.

Wise RA (1989). The brain and reward. In: Liebman JM, Cooper SJ (eds) The Neuropharmacological Basis of Reward. Oxford University Press: New York. pp 377-424.

Young RD (1965). Influence of neonatal treatment on maternal behavior: a confounding variable. Psychonom Sci 3: 295-296. 